\title{
Threats to Mammals on Fragmented Habitats around Asella Town, Central Ethiopia
}

\author{
Mohammed Kasso and Afework Bekele \\ Department of Zoological Sciences, Addis Ababa University, P.O. Box 1176, Addis Ababa, Ethiopia \\ Correspondence should be addressed to Mohammed Kasso; muhesofi@yahoo.com
}

Received 5 August 2014; Revised 16 September 2014; Accepted 30 September 2014; Published 29 October 2014

Academic Editor: Rafael Riosmena-Rodríguez

Copyright (C) 2014 M. Kasso and A. Bekele. This is an open access article distributed under the Creative Commons Attribution License, which permits unrestricted use, distribution, and reproduction in any medium, provided the original work is properly cited.

\begin{abstract}
Assessment of the current information on the major threat to mammals in fragmented remnant montane forest of Child Care Center and School of Agriculture was conducted from March to July 2013. The prevailing threatening factors were collected by questionnaires, checklists, interview, observation, and document analysis. A total of 22 species of mammals were recorded of which six $(27 \%)$ were endemic to the country and vulnerable. Mammals and their habitats were threatened by land fragmentation, hunting, habitat modification, land degradation and deforestation, lack of awareness, and finance. Although all mammals were susceptible to hunting, high rate of occurrence was recorded for Olive baboon (Papio anubis). The different infrastructure construction in both compounds is causing different impacts. As the area is rich in mammals and other species and threatened by different factors to reverse the situation, urgent conservation action is highly recommended.
\end{abstract}

\section{Introduction}

Habitat fragmentation is splitting of natural habitats and ecosystems into smaller, more isolated patches driven by many different factors like disturbance, pollution, settlement, infrastructure, and deforestation [1]. It is the main process responsible for biodiversity loss and threat in tropical forests leading to isolation [2]. Conversion to agricultural land use results in a loss of habitat, reduction in patch size, and an increase in distance between patches and new habitat formation [3]. Habitat loss has pervasive and disruptive impacts on the biodiversity and its magnitude of the ecological impacts can be exacerbated by habitat fragmentation [4].

Anthropogenic activities were frequently related in many ways to forest fragmentation and alteration of natural communities [2]. Land transformation severely affects the integrity of ecological systems through loss of native species, invasion of exotic species, pronounced soil erosion, and decreased water quality [5]. Human activities like tourism practices, hunting, agriculture, and cattle rearing are also known to affect the demography, population structure, spatial range of individuals and species, and change in the community structure [2].
Although the mechanism of impact on populations is poorly known, habitat fragmentation is often considered as a major threat and endangerment to biodiversity [6]. As the proportion of suitable habitat decreases, small and isolated habitat patches appear whose patch size and degree of isolation influence the population size of individual species [3]. This leads species to depend on increasingly smaller patches of remnant, seminatural habitat and green corridors such as hedgerows, wooded field margins, infrastructure verges, and small forest patches [7]. The impacts can also occur in a number of ways: introduction of exotic species, invasion by competitors, nest predators, or nest parasites and the alteration of microclimatic conditions by disturbances like fire, damage to vegetation, off-road vehicle use, poaching, plant collecting, and refuse dumping [8]. Crop cultivation, pasture, and human residence near the fragmented forest habitat also highly determine the species composition and abundance of mammals $[2,5]$. Species composition and abundance change as fragmentation occurs in landscapes by losing those species that require large areas. In addition, the native vegetation left after such modifications may also be reduced in size and disconnected from adjacent, continuous habitat. As a result, plants and animals which occur in these remnants 


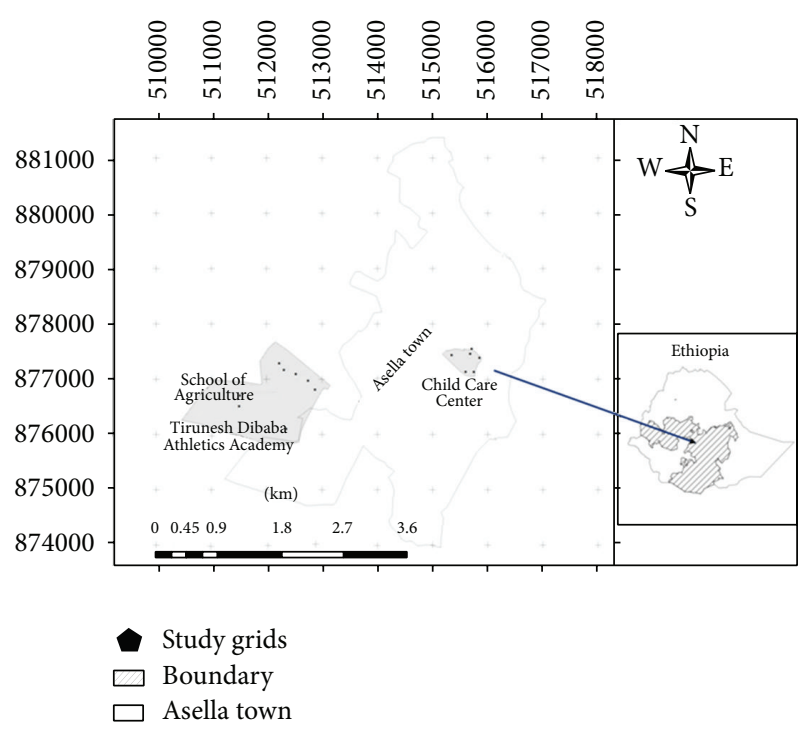

FIgURE 1: Map of the study area.

will be subdivided and reduced. This excludes certain species or increases the probability of extinction $[4,5]$. The rate of species extinction in an isolated patch is inversely related to the size because it less likely provides food, cover, and other resources necessary to support the native wildlife community $[9,10]$.

It also creates discontinuities or patchiness in the distribution of critical resources for animals. Ultimately, these physical changes in the extent and connectivity of suitable habitat conditions affect many processes that influence the behavior and spatial habitat use patterns and intra- and interspecific interactions that influence population persistence and community structure and dynamics [11].

Despite decades of research, the general importance of patch area and isolation as predictors of species occupancy in fragmented tropical terrestrial systems remains unknown [2]. Furthermore, the sensitivity to patchiness and isolation depends on taxonomic group, diet, specialization and fecundity, and size of mammals due to their variation in their energy requirements [12]. Although the ecological consequences by human disturbance near development seem severe, only limited research has addressed its effect on animal communities $[13,14]$. Studying the socioeconomic variables directly connected to wildlife habitat is used to predict the influence of human presence and activities on small mammal communities and it can be used as a tool to evaluate the conservation status and threat [2]. Humans greatly alter the landscape patterns that frequently correlate with species assemblages including the amount and structure of native vegetation, the prevalence of anthropogenic edges, the degree of landscape connectivity, and the structure and heterogeneity of modified areas [15].

Since the consequence of habitat fragmentation to animals is complex, species respond differently to the loss and isolation of habitats. Species with limited mobility, large area requirements, and strong dependence on a certain type of habitat will be more affected by habitat loss and isolation [7].
The abundance and richness of mammal assemblages considerably differ among remnant fragments in urban and rural areas. The urban fragments seem to possess high proportion of introduced rodents than rural and forest fragments isolated by urbanization. Larger areas with good quality habitats are not sufficient to maintain native small mammal population [16].

Many habitats of mammals are undergoing degradation due to high human encroachment for agriculture, pastureland, collection of firewood and medicinal plant, settlement, and other human activities [17]. Even though Ethiopia possesses many mammalian fauna, limited studies have been carried out in different parts of the country with focus on large intact and protected habitats $[18,19]$. However, there is no sufficient study on such small fragmented habitats that could serve as population stock source with significant economical, ecological, social, and cultural values. Despite this, little attention is given to conserve the biodiversity of the area and the country as a whole. Thus, the present study is aimed at gathering the current information on the prevailing threatening factors to mammals. The study will also be used to suggest possible solutions for conservation and development of the area.

\section{Materials and Methods}

2.1. The Study Area. The study is carried out in the two remnant fragmented dry evergreen montane forest habitats located approximately $07^{\circ} 55^{\prime} 22^{\prime \prime}$ to $07^{\circ} 56^{\prime} 24^{\prime \prime} \mathrm{N}$ latitude and $39^{\circ} 05^{\prime} 41^{\prime \prime}$ to $39^{\circ} 08^{\prime} 36^{\prime \prime} \mathrm{E}$ longitude in and around Asella town. The remnant fragmented forests were Ethiopian Orthodox Church Child and Family Affairs Organization, Debre Kidus Sisay Hailemichael Memorial Child Care Center of Asella town, hereafter, called Child Care Center and Adama Science and Technology University, School of Agriculture, hereafter, called School of Agriculture. The Child Care Center is of relatively small size 22.11 ha $\left(221,100 \mathrm{~m}^{2}\right)$ when compared with School of Agriculture which is about 261.05 ha $(2,610$, $540 \mathrm{~m}^{2}$ ) (Figure 1).

These fragmented ruminant forests were protected and modified for use of land for different purposes before long time. This helped the fragmented habitats to serve as best representative of the surrounding area before it was deforested. In general, the fragmented habitats have thick mixed natural and plantation forest dominated by Podocarpus trees that endowed with many small and large mammals like bushbuck, baboon, hyena, porcupine, rat and mice, and other organisms. Currently due to the expansion of Asella town, human population growth, and different development and infrastructure construction, the habitat in both compounds is affected by loss of corridors and edge effect.

2.2. Methods. Data on prevailing threatening factors were collected with the help of semistructured open and closeended questionnaires and checklists, interview, and direct and indirect observation from March to July 2013. A pretested structured questionnaire in the form of interview was administered to a total of 30 respondents selected by systematic random sampling from communities adjacent to and inside the fragmented habitats. 
In addition, semistructured interviews were also conducted on 10 key informants from workers of both compounds to gather information about species of mammals found in the area and their conservation status including threatening factors for them and their habitats. Furthermore, transect walk was used for cross check on similar information on the subject. Trapping, line transects, and indirect survey techniques were used to survey mammals. Preprepared data sheet and checklist were also used to record exotic species, intruders, and other threatening factors.

The prevailing threatening factors were analyzed qualitatively based on the information gathered from observation, measurements, interview, and focus group discussion with the key informant and from status and type of species recorded in the area. The collected data were tabulated and organized. Both qualitative and quantitative data were analyzed with appropriate statistical methods such as mean, percentage, and Chi-square test. The statistical significance was tested at $P<0.05$. SPSS Version 16.0 statistical program and PAST version 1.62 Statistical Package (software) were used.

\section{Results}

During the study period, 22 species of mammals were recorded of which six $(27 \%)$ were endemic to the country and vulnerable. Some of these species were Abyssinian grass rat (Arvicanthis abyssinicus), Ethiopian forest brush-furred rat (Lophuromys chrysopus), Mahomet's mouse (Mus mahomet), gray tailed narrow-headed rat (Stenocephalemys griseicauda), white footed rat (Stenocephalemys albipes), and Menelik's bushbuck (Tragelaphus scriptus menelik). Other species like African striped weasel (Poecilogale albinucha) and serval (Leptailurus serval) were rare and recorded from limited sites (Table 1).

Except for some small mammals, all the remaining medium and large mammals require wide home range which should be larger than the existing habitats in both fragmented remnant forest of the Child Care Center and the School of Agriculture. The existing home range is not sufficient and safe for crested porcupine (Hystrix cristata), Vervet monkey (Chlorocebus pygerythrus), Olive baboon (Papio anubis), Oribi (Ourebia ourebi), common duiker (Sylvicapra grimmia), spotted hyena (Crocuta crocuta), and aardvark (Orycteropus afer). As the result of the requirement for relatively large home range and absence of sufficient resources for their daily requirement in the compound, they were forced to move to the nearby habitat. In the process, they cause damage to the local community which in turn increases the risk of hunting.

Although all mammals were susceptible to hunting, high rate of incidence of hunting was recorded for Papio anubis. The extent of damage was high to the local community, agricultural crops, and plantations. Its high damage to natural forest and artificial plantation through debarking and destroying the young and seedling plants was also observed. These activities resulted in high number of killings. Olive baboons also kill and eat the young of Tragelaphus scriptus menelik. Predation of the young is the major concern in reducing the number leading to conservation threat. Chlorocebus pygerythrus is also a major pest on crops resulting in hunting. Even though currently hunting is legally prohibited, T. menelik and S. grimmia were commonly hunted for bush meat. In addition, the three dogs in the Child Care Center challenge the nocturnal animals like Civettictis civetta, $C$. crocuta, Leptailurus serval, Herpestes sanguineus, $H$. cristata, Poecilogale albinucha, and O. afer.

Besides predation by dogs and cats, mammals face problems of cattle overgrazing and competition for food resource. Despite the smallness of grassland habitat in Children Care, there were a total of 11 cattle which graze in the compound. They cause overgrazing on all available grassland and in small open woodland habitats aggravating the shortage of food and creating intensive competition with grazer mammals particularly for T. menelik. In the same way, more than 350 cattle that belonged to the academy and Asella Model Agricultural Enterprise graze in the compound of the School of Agriculture. Unlike Child Care Center, these cattle cause comparatively less impact on the survival of mammals because of its large size of grassland habitat and provision with supplementary forage. Furthermore, in both compounds there was large number of livestock that graze the surrounding area from outside. They cause severe overgrazing around the edge of both compounds.

Many of the relatively abundant mammals documented were habitat specialists. The modification, degradation, and fragmentation of these remnant forests affect the animals. Particularly sensitive mammals such as T. menelik and $C$. guereza will be more affected by it. Ourebia ourebi was also under threat by loss of habitat due to the construction activity.

Most (77\%) of the respondents believed that the habitat was suitable for mammals. However, $23 \%$ of them stated that the habitat is not suitable for all mammals. The variation was statistically significant $\left(\chi^{2}=8.533 ; \mathrm{df}=1 ; P<0.05\right)$. Due to shortage and insufficient resources, they were forced to come out from the compound in search of food. Eventually this makes them to be pest for the surrounding local community. This resulted in the human wildlife conflict leading to the risk of hunting.

Availability of corridors that allow animals to move freely from compound to other site for their requirement was confirmed by $63 \%$ of respondents as either excellent or very good and $37 \%$ believed them to be good (Table 2). The perception on the availability of corridor for mammals was not statistically significant $\left(\chi^{2}=2.6 ; \mathrm{df}=2 ; P>\right.$ $0.05)$. The reasons mentioned were because of the existence of agricultural cropland and some fragmented forest and plantations around the human residence in the parts not occupied by the urban settlements. Since the area was highly disturbed by anthropogenic activities, the movements of animals frequently shifted during the time in which human activity was reduced like in the morning, evening, and night.

The extent of protection of mammals and their habitats from illegal intruders, poachers, and hunters was poor by most respondents. This was mainly attributed to the insufficient number of guards in both compounds, lack of fence and its maintenance, lack of awareness of local community in protecting wildlife and its habitat, the existence of church and other service providing facilities for the local community, 
TABLE 1: List of species of mammals recorded from different habitats in the study area.

\begin{tabular}{|c|c|c|c|}
\hline Order & Species & Common name & Species authority \\
\hline \multirow{10}{*}{ Rodentia } & Arvicanthis abyssinicus ${ }^{*}$ & Abyssinian grass rat & Rüppell, 1842 \\
\hline & Hystrix cristata & Crested porcupine & Linnaeus, 1758 \\
\hline & Lophuromys chrysopus* & Ethiopian forest brush-furred rat & Osgood, 1936 \\
\hline & Lophuromys flavopunctatus & Yellow spotted brush-furred rat & Thomas, 1888 \\
\hline & Mastomys natalensis & Natal multimammate mouse & Smith, 1834 \\
\hline & Mus mahomet ${ }^{*}$ & Mahomet's mouse & Rhoads, 1896 \\
\hline & Rattus rattus & House rat & Linnaeus, 1758 \\
\hline & Stenocephalemys griseicauda* & Gray tailed narrow-headed rat & Frick, 1972 \\
\hline & Stenocephalemys albipes* & White footed rat & Rüppell, 1842 \\
\hline & Tachyoryctes splendens & East African mole rat & Rüppell, 1835 \\
\hline \multirow{3}{*}{ Primate } & Chlorocebus pygerythrus & Vervet monkey & Cuvier, 1821 \\
\hline & Colobus guereza & Eastern black-and-white colobus & Rüppell, 1835 \\
\hline & Papio anubis & Olive baboon & Lesson, 1827 \\
\hline \multirow{3}{*}{ Cetartiodactyla } & Ourebia ourebi & Oribi & Zimmermann, 1783 \\
\hline & Sylvicapra grimmia & Common duiker & Linnaeus, 1758 \\
\hline & Tragelaphus scriptus menelik* & Menelik's bushbuck & Neumann, 1902 \\
\hline \multirow{5}{*}{ Carnivora } & Civettictis civetta & African civet & Schreber, 1776 \\
\hline & Crocuta crocuta & Spotted hyena & Erxleben, 1777 \\
\hline & Leptailurus serval & Serval & Schreber, 1776 \\
\hline & Herpestes sanguineus & Slender mongoose & Rüppell, 1835 \\
\hline & Poecilogale albinucha & African striped weasel & Gray, 1864 \\
\hline Tubulidentata & Orycteropus afer & Aardvark & Pallas, 1766 \\
\hline
\end{tabular}

*Endemic to Ethiopia.

TABLE 2: Perception of local communities on the conservation of mammals and their habitats in the study area (number in the bracket refers to percentage).

\begin{tabular}{|c|c|c|c|c|}
\hline \multirow{2}{*}{ Items } & \multicolumn{4}{|c|}{ Percentage level $(n=30)$} \\
\hline & Excellent & Very good & Good & Poor \\
\hline Habitat suitability for all mammals & $0(0)$ & $23(77)$ & $7(23)$ & $0(0)$ \\
\hline Availability of resources for all mammals in the compound & $3(10)$ & $16(53)$ & $6(20)$ & $5(17)$ \\
\hline Extent of protection of domestic animals & $7(23)$ & $23(77)$ & $0(0)$ & $0(0)$ \\
\hline $\begin{array}{l}\text { Availability of corridors that allow animals to move freely from } \\
\text { compound to other sites for their requirement }\end{array}$ & $6(20)$ & $13(43)$ & $11(37)$ & $0(0)$ \\
\hline Extent of protection from illegal intruders, poachers, and hunters & $4(13)$ & $7(23)$ & $0(0)$ & $19(63)$ \\
\hline Extent of disturbance from human movement in the compound & $17(57)$ & $4(13)$ & $3(10)$ & $6(20)$ \\
\hline Availability of protection rules and regulation and their enforcement & $0(0)$ & $7(23)$ & $9(30)$ & $14(47)$ \\
\hline
\end{tabular}

low enforcement of the law, urbanization, children residence, students, and workers.

Local communities also stated that there was high disturbance in wildlife by the different facilities and services provided in both compounds (Table 2). For example the existences of church, children residence, clinic, student dormitory, offices and different buildings, barn, road, farmland, livestock rearing, and crop cultivation contributed to the factors that threatened mammals and their habitats. Nevertheless, in both compounds, there were many activities carried out to conserve the existing mammals and their habitat like plantations with indigenous tree and protection from hunters and poachers.

In both compounds, there was no strong rule and regulation to protect the mammals and their habitats with the exception of enforcements. In most reports, enforcing the rule and regulation was weak.

Almost all respondents accepted that the importance of conserving the area was from its environmental service, climate change mitigation, tourist attraction, and heritage. Furthermore, $99.4 \%$ of the respondents agreed that conserving the ruminant forest and the existing wildlife will help to 
develop the area into Urban Park in order to attract tourists for income generation (Table 2).

\section{Discussion}

One of the immediate consequences of habitat fragmentation is the disruption of movement patterns and the resulting isolation of individuals and local populations [11]. All the species recorded in the present study have natural ability to disperse as the surrounding habitat is highly modified and occupied by urban residence; it reduced the dispersal ability of animals. Home range compaction provides a mechanism increasing densities to small fragments. The demographic consequences resulted from the high densities might lead to damage further habitats, predation, and reduce diversity [6]. Increases in density and compaction of home ranges have a potential for changes in social and mating systems. Density is frequently associated with changes in social organization and space use. Increased interaction rate leads to weight loss and reduced frequency of reproduction. Damage to trees, such as bark stripping and girdling, increases with increasing density and may result in human-wildlife conflict [6].

Although infrastructures may represent a significant barrier to their movement, local populations can be sustained so long as the habitat remnants remain sufficiently large. Isolation effects manifest themselves in this group of species through long-term demographic and genetic change within the population [7]. Five major categories of primary effects can be distinguished by the physical presence of the infrastructure: habitat loss (land occupation, disturbance, and barrier effects), disturbance or edge effects resulting from pollution of the physical, chemical, and biological effects, mortality (road side kill), barriers making the habitats inaccessible leading to isolation of the population, and corridor. This can also facilitate the invasion of nonnative and sometimes pest species [7]. The different infrastructure construction in both compounds causes impacts like disturbance by human activity, loss and modification of the mammal natural habitat, hunting, and competition for resource and exotic species introduction. Particularly, the underway infrastructure construction activity of the Athlete Tirunesh Dibaba Athletics Academy had great impact in most suitable habitats of $O$. ourebi. Detailed study on the level of disturbance by infrastructure construction and its operation is lacking. However, species with large body size, long-lived, relatively low reproductive rate, habitat specialists and rare are most vulnerable to its disturbance [7].

Habitat connectivity helps to connect habitat patches and enables the movement of an animal. It becomes effective when the distances between adjacent patches are short enough to allow individuals to cross easily on a daily basis. For this, hedgerows and field margins, rivers, road verges, and power-lines serve ecological corridors [7]. In both fragmented remnant forest habitats, there was loss of corridors. Except in a few places, most of the patch forests were deforested and the remaining ones were occupied by different human settlement and infrastructure. Habitat corridors serve as an alternative for connectivity in fragmented landscapes, minimizing the effects of structural isolation [10]. Corridors in addition to its facilitation for the movement of individuals between different habitat patches (fragments) can also be used as habitats [10]. In a highly fragmented agricultural landscape with small patches of native vegetation, corridors can be used by mammals [20]. Habitat fragmentation is often associated with population decline and increased risk of extinction. It is considered as one of the greatest threats to biodiversity [21].

In fragmented landscapes, the development of sustainable management strategies and habitat conservation plans for native species is thus urgently needed, particularly in the context of habitat restoration.

The effects of human disturbance on mammals were substantial. Richness and abundance of mammals were reduced in more disturbed sites while in some cases the disturbance might favor some mammals. This is due to habitat preference of individual species variation in response to habitat alteration. In most cases, similar results of variation in species richness are associated with increased habitat alteration. An important factor acting as barriers in fragmented landscape is road construction, where roads divide population into small fragments, leading them to extinction [22]. Roads contribute directly to mortality of species when they disperse [23].

As the proportion of suitable habitat decreases in the landscape, area and isolation effects start influencing the population size of the species. Hence, the relative importance of habitat loss, patch size, and isolation is expected to differ at different degrees of habitat fragmentation [3]. Landscapes with highly fragmented habitat, patch size, and isolation complement the effect of habitat loss and the loss of species or decline in population size will be greater than expected from habitat loss alone [3]. Habitat fragmentations are parts of the landscape mosaic and the presence of a species in a patch may be a function not only of patch size and isolation, but also of the neighboring habitat. Habitat generalists may survive in very small patches because they can also utilize resources in the surrounding areas. Furthermore, the species diversity across habitats in a given landscape may increase when new patches of habitats are created within the continuous habitat, because new species may be found in these new habitats, even if they are human made [3].

Edges tend to concentrate and funnel human activities such as littering, drift of fertilizers, trampling from domestic animals, grazing, escaping fires, hunting, poaching, and excessive human disturbance [11]. For example, due to the preference for edge by most game species, hunting is often concentrated along edges. Roads are linear landscape features that produce a disproportionately large amount of edge for their area and provide human access and a source of disturbance. Roads provide access for hunters, so hunting is often concentrated along road edges. Road edges can be a source of exotic plants that invade adjacent habitats. Additional edge effects around roads result from disturbance by traffic noise and road kill [11].

\section{Conclusion and Recommendations}

The relatively intact nature of the fragmented habitat can be used as a good indicator for the extent of quality and 
suitability of habitats for mammals and others. In both compounds, beside the protection of natural forest, there was a plantation practice with indigenous and exotic species. Nevertheless, the fragmented habitats were threatened by different natural and anthropogenic activities serving better refugia for different mammals and other organisms. The conservation of mammals and their habitat plays a great role in providing environmental services like climate change mitigation, tourist attraction and income generation, and social and cultural heritage. The outlook of such provision services also contributed for positive attitude development and initiation in protecting the area with its biodiversity. Moreover, since the surrounding habitat was degraded and defrosted, the existing small remnant natural forest in the compound of the Child Care Center and the School of Agriculture was acting as the only surviving option and refugia for diverse species of mammals. It also acted as exemplary site that was used as heritage and witness for historical forest appearance of the surrounding habitat before its deforestation and degradation. It can also be used to teach the current generation on the impacts of anthropogenic activity and value of conservation.

Conserving the habitats as well as the species has great ecological, economical, and social values. Therefore, to maintain and conserve the mammals and their habitats with other biodiversity, the following recommendations are forwarded.

(1) The current urban expansion and the large number of people living close to both fragmented remnant forest habitats pose serious problems in the conservation and protection of mammals and their habitats. Thus, to reverse the situation, appropriate urban master plan and land use system is mandatory.

(2) Domestic animals like dog, cat, and livestock were becoming one of the threatening factors for mammal conservation. In particular, the high number of livestock grazing inside the compound was causing overgrazing and depletion of resources for wildlife. Beside this, the expansion and practice of farmlands in the School of Agriculture and surrounding area of both compounds have led to further habitat degradation, isolation, loss of corridors, and hunting pest mammals. Hence environmental friendly activity and mechanisms should be identified and applied accordingly.

(3) Investment for the development activities is important for the development and wellbeing of the nation. However, if the correct environmental impact assessment is not well conducted, it will have tremendous impact on the wildlife and their habitat. Hence, taking proper care and controlling and managing the activity of the academy are mandatory for protection of mammals and their habitats.

(4) The weak level of protection of mammals and their habitats from illegal intruders, poachers, and hunters should be improved through local community awareness, constructing, and maintaining fence, employing enough number of guards and controlling the movement and activity of resident people. In addition, service giving facilities and infrastructures must be constructed in the way that they do not disturb biodiversity and animals habitats.

(5) As pest mammals, $P$. anubis is causing great damage leading to risk of hunting and bad public image. Ecological based control method should be sought rather than the current method of hunting.

(6) The present plantation practice with indigenous plant species in both compounds should be encouraged.

\section{Conflict of Interests}

The authors declare that there is no conflict of interests regarding the publication of this paper.

\section{Acknowledgments}

The authors thank Abebe Getahun, Chemera Zewdie, Teshoma Cheru, and Girma Alemu for their support and facilitation. They thank Kedir Adem, for helping them in developing the map of the study area. They also express their special appreciation to all staff of the Debir Kidus Sisay Hailemichael Memorial Child Care Center and respondents for their support in providing them with important information. They thank Department of Zoological Sciences, Addis Ababa University, for material and financial support.

\section{References}

[1] G. J. Bekker, "Introduction," in Habitat Fragmentation due to Transportation Infrastructure. The European Review, M. Trocmé, S. Cahill, H. J. G. de Vries et al., Eds., pp. 15-17, Official Publications of the European Communities, Luxembourg, Belgium, 2003.

[2] N. Olifiers, R. Gentile, and J. T. Fiszon, "Relation between smallmammal species composition and anthropic variables in the Brazilian Atlantic Forest," Brazilian Journal of Biology, vol. 65, no. 3, pp. 495-501, 2005.

[3] H. Andren, "Effects of habitat fragmentation on birds and mammals in landscapes with different proportions of suitable habitat: a review," Oikos, vol. 71, no. 3, pp. 355-366, 1994.

[4] R. M. Ewers and R. K. Didham, "Confounding factors in the detection of species responses to habitat fragmentation," Biological Reviews of the Cambridge Philosophical Society, vol. 81, no. 1, pp. 117-142, 2006.

[5] S. K. Collinge, "Ecological consequences of habitat fragmentation: implications for landscape architecture and planning," Landscape and Urban Planning, vol. 36, no. 1, pp. 59-77, 1996.

[6] J. L. Koprowski, "The response of tree squirrels to fragmentation: a review and synthesis," Animal Conservation, vol. 8, no. 4, pp. 369-376, 2005.

[7] A. Seiler, "Key ecological concepts," in Habitat Fragmentation due to Transportation Infrastructure. The European Review, M. Trocmé, S. Cahill, H. J. G. de Vries et al., Eds., pp. 19-29, Official Publications of the European Communities, Luxembourg, 2003.

[8] R. M. Sauvajot, M. Buechner, D. A. Kamradt, and C. M. Schonewald, "Patterns of human disturbance and response by small mammals and birds in chaparral near urban development," Urban Ecosystem, vol. 2, pp. 279-297, 1998. 
[9] R. H. MacArthur and E. O. Wilson, The Theory of Island Biogeography, Princeton University Press, Princeton, NJ, USA, 1967.

[10] A. O. Mesquita and M. Passamani, "Composition and abundance of small mammal communities in forest fragments and vegetation corridors in Southern Minas Gerais, Brazil," Revista de Biologia Tropical, vol. 60, no. 3, pp. 1335-1343, 2012.

[11] K. McGarigal, S. Cushman, and C. Regan, Quantifying Terrestrial Habitat Loss and Fragmentation: A Protocol, Department of Natural Resources Conservation, University of Massachusetts, Massachusetts, Mass, USA, 2005.

[12] L. R. Prugh, K. E. Hodges, A. R. E. Sinclair, and J. S. Brashares, Effect of Habitat Area and Isolation on Fragmented Animal Populations, The National Academy of Sciences of the USA, Washington, DC, USA, 2008.

[13] P. Matson, "The use of urban gradients in ecological studies," Ecology, vol. 71, pp. 12-31, 1990.

[14] R. B. Blair, "Land use and avian species diversity along an urban gradient," Ecological Applications, vol. 6, no. 2, pp. 506-519, 1996.

[15] J. Fischer and D. B. Lindenmayer, "Landscape modification and habitat fragmentation: a synthesis," Global Ecology and Biogeography, vol. 16, no. 3, pp. 265-280, 2007.

[16] I. C. Fernández and J. A. Simonetti, "Small mammal assemblages in fragmented shrublands of urban areas of Central Chile," Urban Ecosystems, vol. 16, no. 2, pp. 377-387, 2013.

[17] G. R. Singleton, H. Leirs, L. A. Hindus, C. J. Krebs, and D. M. Sparatt, Rats, Mice, and People: Rodent Biology and Management, Australian Center for International Agricultural Research, Canberra, Australia, 2003.

[18] A. Bekele, "Population dynamics of the Ethiopian endemic rodent Praomys albipes in the Menagesha State Forest," Journal of Zoology, vol. 238, no. 1, pp. 1-12, 1996.

[19] A. Bekele and M. Corti, "Forest blocks and altitude as indicators of Myomys albipes (Rüppell 1842) (Mammalia Rodentia) distribution in Ethiopia," Tropical Zoology, vol. 10, no. 2, pp. 287-293, 1997.

[20] M. C. Lyra-Jorge, G. Ciocheti, and V. R. Pivello, "Carnivore mammals in a fragmented landscape in northeast of São Paulo State, Brazil," Biodiversity and Conservation, vol. 17, no. 7, pp. 1573-1580, 2008.

[21] W. F. Laurance, L. V. Ferreira, J. M. de Merona, and S. G. Laurance, "Rain forest fragmentation and the dynamics of Amazonian tree communities," Ecology, vol. 79, no. 6, pp. 2032-2040, 1998.

[22] G. K. Meffe and C. R. Carroll, Principles of Conservation Biology, Sinauer Associate, Sunderland, Mass, USA, 2nd edition, 1997.

[23] K. F. Davies and C. R. Margules, "Effects of habitat fragmentation on carabid beetles: experimental evidence," Journal of Animal Ecology, vol. 67, no. 3, pp. 460-471, 1998. 

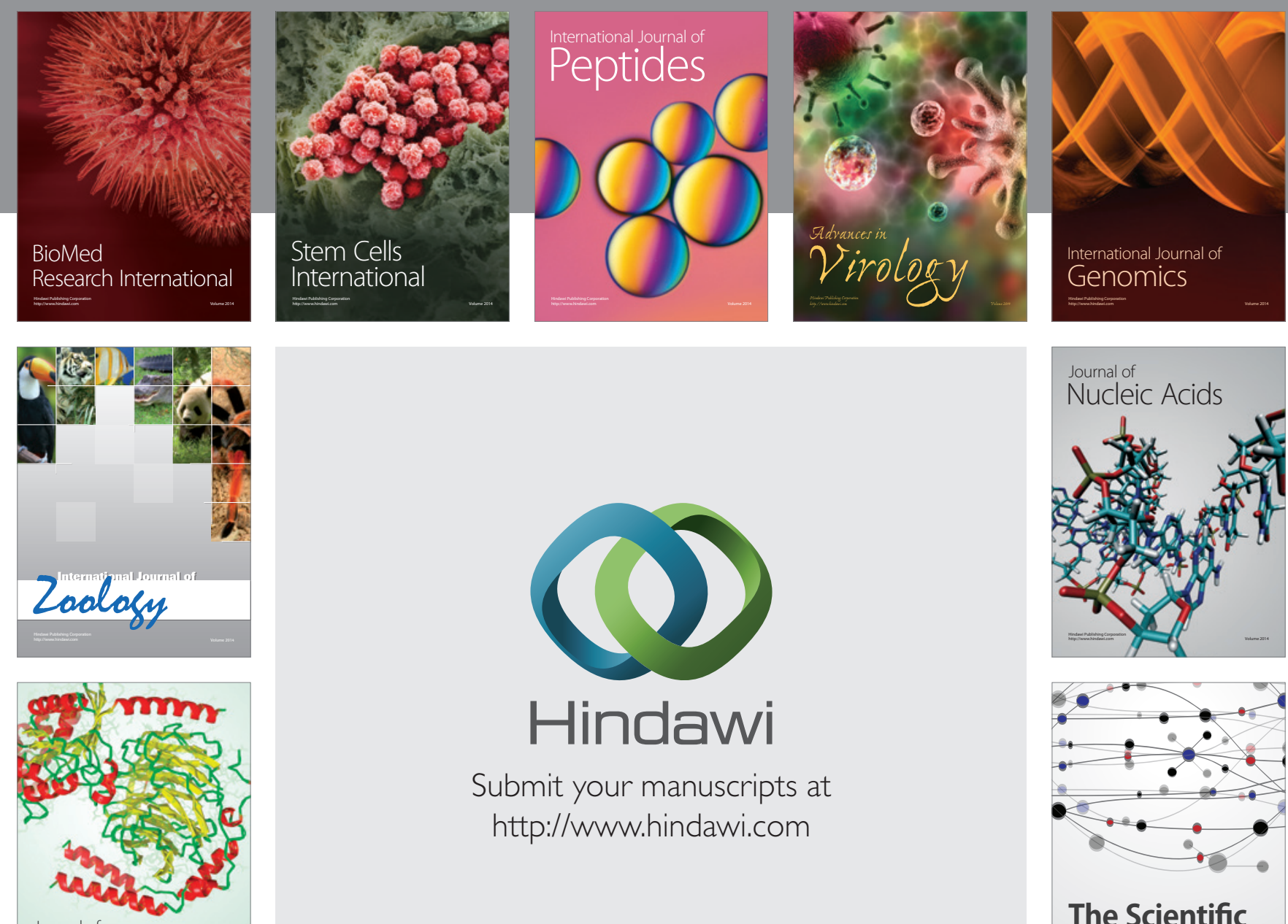

Submit your manuscripts at

http://www.hindawi.com

Journal of
Signal Transduction
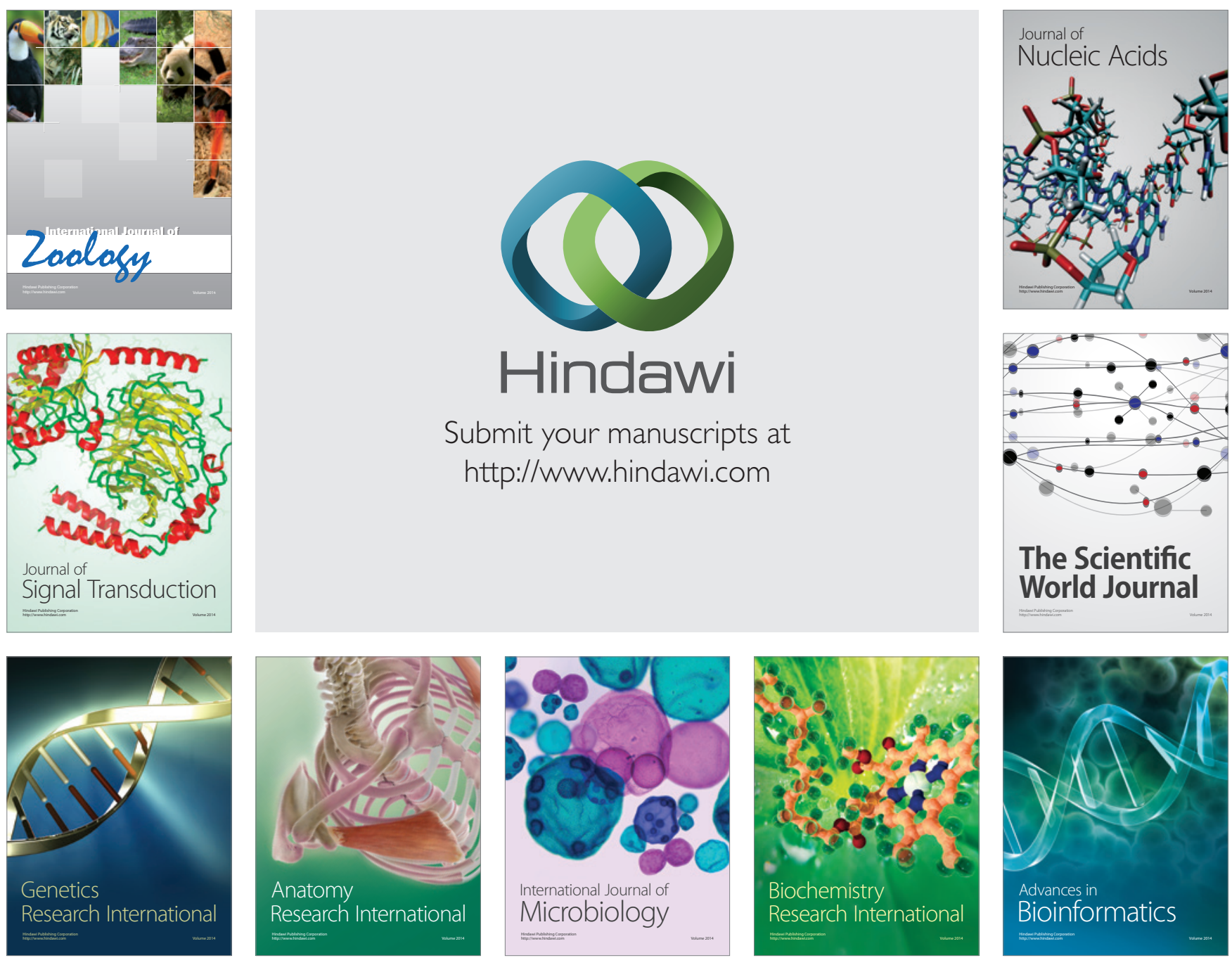

The Scientific World Journal
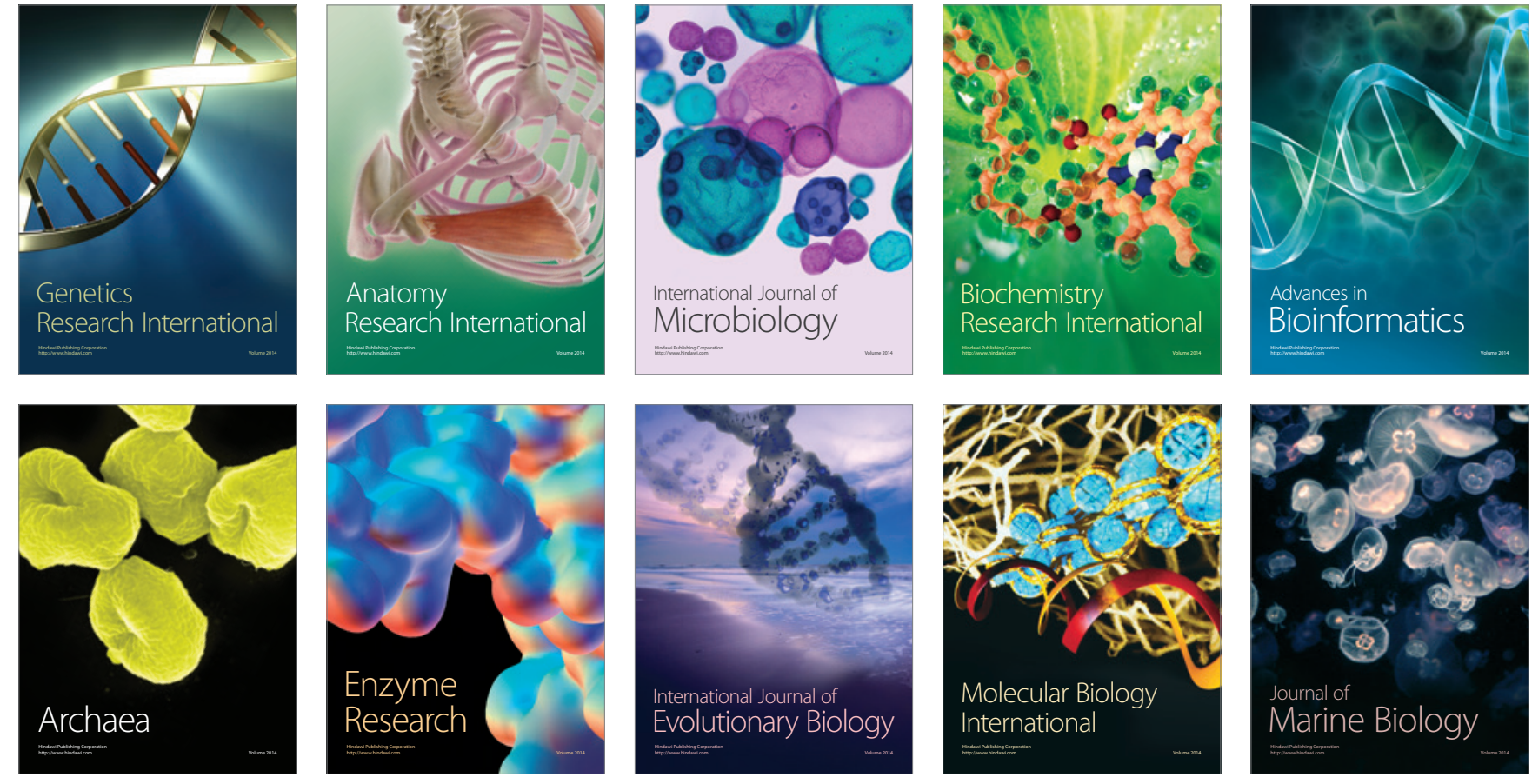